\title{
A SAGE based approach to human glomerular endothelium: defining the transcriptome, finding a novel molecule and highlighting endothelial diversity
}

Guerkan Sengoelge ${ }^{1^{*}+}$, Wolfgang Winnicki ${ }^{1 \dagger}$, Anne Kupczok ${ }^{2}$, Arndt von Haeseler ${ }^{2}$, Michael Schuster ${ }^{3}$, Walter Pfaller ${ }^{4}$, Paul Jennings ${ }^{4}$, Ansgar Weltermann ${ }^{5}$, Sophia Blake ${ }^{6}$ and Gere Sunder-Plassmann ${ }^{1}$

\begin{abstract}
Background: Large scale transcript analysis of human glomerular microvascular endothelial cells (HGMEC) has never been accomplished. We designed this study to define the transcriptome of HGMEC and facilitate a better characterization of these endothelial cells with unique features. Serial analysis of gene expression (SAGE) was used for its unbiased approach to quantitative acquisition of transcripts.

Results: We generated a HGMEC SAGE library consisting of 68,987 transcript tags. Then taking advantage of large public databases and advanced bioinformatics we compared the HGMEC SAGE library with a SAGE library of non-cultured ex vivo human glomeruli (44,334 tags) which contained endothelial cells. The 823 tags common to both which would have the potential to be expressed in vivo were subsequently checked against 822,008 tags from 16 non-glomerular endothelial SAGE libraries. This resulted in 268 transcript tags differentially overexpressed in HGMEC compared to non-glomerular endothelia. These tags were filtered using a set of criteria: never before shown in kidney or any type of endothelial cell, absent in all nephron regions except the glomerulus, more highly expressed than statistically expected in HGMEC. Neurogranin, a direct target of thyroid hormone action which had been thought to be brain specific and never shown in endothelial cells before, fulfilled these criteria. Its expression in glomerular endothelium in vitro and in vivo was then verified by real-time-PCR, sequencing and immunohistochemistry.
\end{abstract}

Conclusions: Our results represent an extensive molecular characterization of HGMEC beyond a mere database, underline the endothelial heterogeneity, and propose neurogranin as a potential link in the kidney-thyroid axis.

Keywords: Bioinformatics, Endothelial diversity, Glomerular endothelial cell, Neurogranin, Serial analysis of gene expression

\section{Background}

Endothelial cells (EC) are frequently thought to be homogenous because of the multiple functions they share independent of the organ they serve, such as providing a non-thrombogenic surface, regulation of production or inhibition of vasoactive substances, haemostasis as well as leukocyte recruitment. Yet on closer examination, they

\footnotetext{
* Correspondence: guerkan.sengoelge@meduniwien.ac.at

${ }^{\dagger}$ Equal contributors

'Department of Medicine III, Division of Nephrology and Dialysis, Medical University of Vienna, Waehringer Guertel 18 - 20, A-1090 Vienna, Austria Full list of author information is available at the end of the article
}

show significant heterogeneity between similar vessels in different organ systems or in arterial versus venous endothelia [1-5]. Although known as highly specialized cells since the description of their fenestrated phenotype by F. Jorgensen more than 40 years ago [6] glomerular endothelial characteristics remain largely undefined.

Global gene expression studies added large amounts of valuable information to our knowledge on various EC and related pathologies, e.g. atherosclerosis [7]. Yet, in the case of human glomerular microvascular endothelial cells (HGMEC) developments did not have comparable 
pace. Due to challenges in obtaining, culturing and maintaining HGMEC studies employing primary cells in human glomerular research have been scarce, but very useful in obtaining new insights of human glomerular endothelium; most recently Amaral et al. investigated how Shiga toxin type- 2 and Subtilase cytotoxin lead to damages characteristic for haemolytic uremic syndrome [8]. The ultimate aim to experiment with non-cultured glomerular EC has never been attained and the very first human glomerular endothelial cell line (GEnC) was not presented until 2006 [9]. This cell line has proved to be a useful tool in kidney research. Recently, glomerular endothelial barrier function and its regulation were finally studied in great detail using this tool while previously filtration barrier function research has mostly been on podocytes and the contribution of the glomerular endothelium had been relatively neglected [10]. These studies showed how reactive oxygen species present in common pathologies such as diabetes cause glomerular injury by directly disrupting glycocalyx and how chondroitin sulphate controlled by vascular growth factors $\mathrm{A}$ and $\mathrm{C}$ contributes to glomerular endothelial glycocalyx modulating the protein passage $[8,11]$. Nevertheless, despite its usefulness in endothelial research an immortalized cell line is not suitable to define the cellular transcriptome with its predominant and specific transcripts. Thus, we hypothesized that such an investigation using genetically unmodified HGMEC would enhance our understanding regarding the source of the unique morphological characteristics, the behaviour in both culture and in disease and prepare the grounds for further studies of HGMEC. We used serial analysis of gene expression (SAGE), because it provides an unbiased approach to gene discovery and enables quantitative acquisition of most transcripts expressed [12]. Secondly, SAGE has become a powerful tool due to creation of large datasets holding more than two hundred million tags from a wide spectrum of tissues or cells including different EC which are publicly available as part of the Cancer Genome Anatomy Project [13].

The goals of this study were to establish extensive transcriptomic data as a step towards identification of the transcripts controlling the distinctive morphological and functional characteristics of glomerular endothelium and to underline endothelial diversity by comparisons between SAGE libraries from glomerular endothelial and uncultured glomeruli or from other non-glomerular EC. To reach these goals based on the known challenge in receiving useful data out of large transcript lists we describe a research strategy powerful enough to first confirm the endothelial origin of the transcript lists by bioinformatics, then to identify a low abundant transcript, neurogranin (NRGN) for the first time in glomerular endothelium using an in-silico analysis and finally to verify its expression in vitro and in vivo by means of sequencing and immunohistochemistry.

\section{Results}

\section{Characterisation of HGMEC}

Primary HGMEC formed monolayers and displayed typical cobblestone morphology (Figure 1A) in phase contrast microscopy. Immunofluorescence studies revealed distinct expression of von Willebrand Factor (vWF) and platelet/endothelial cell adhesion molecule 1 (PECAM1, CD31). Von Willebrand Factor staining demonstrated discrete, granular, perinuclear localisation (Figure 1B), whilst CD31 was expressed at the region of cell-to-cell contacts (Figure 1C). HGMEC retained functional characteristics of the microvasculature, expressing E-selectin and Pselectin $(\mathrm{CD} 62 \mathrm{E} / \mathrm{P})$ in response to tumor necrosis factor (TNF) stimulation (Figure 1D), whereas unstimulated cells did not (Figure 1E).

Transmission electron microscopy showed the presence of rod shaped microtubulated Weibel-Palade bodies (Figure 2A and B) which unambiguously identify the cells as endothelial [14]. Scanning electron microscopy demonstrated numerous fenestrae with a diameter of approx. $100 \mathrm{~nm}$ (Figure 2C). The presence of fenestrae as a hallmark of glomerular endothelial reflects the welldifferentiated status of these cells [15].

\section{HGMEC SAGE library}

The final HGMEC SAGE library which was constructed using the short SAGE protocol as it is superior to the long SAGE protocol in identifying differential expression of tags [16] contained 68,987 tags with 18,385 unique tags after electronic removal of contaminating linker sequences (Additional file 1: Table S1). It has been approved by the Gene Expression Omnibus (GEO) data depository (http://www.ncbi.nlm.nih.gov/geo) and assigned an accession number [GEO:GSM16892]. Key features of this library are shown in Table 1.

\section{Verification of endothelial origin of HGMEC SAGE library}

The library was confirmed to be of endothelial origin with a classification approach as explained in detail in the Methods section. In short, we used the sum of the relative expression of 150 tags (Additional file 2: Table S2) as a test statistic: a value larger than the threshold 0.022 indicates an endothelial origin. In other words, if the sum of the total copy numbers of these tags account for $2.2 \%$ or more, that library qualifies as endothelial. With a sum of $0.070(7 \%)$ for these 150 tags our HGMEC SAGE library is clearly classified to be of endothelial origin (Figure 3). Notably, two of the analyzed 18 endothelial cell SAGE libraries, "Vascular_endothelium_normal_ breast_associated_P1H12 +_AP_1” [GEO: GSM384017] and "Normal corneal endothelium" [GEO: GSM1652], 

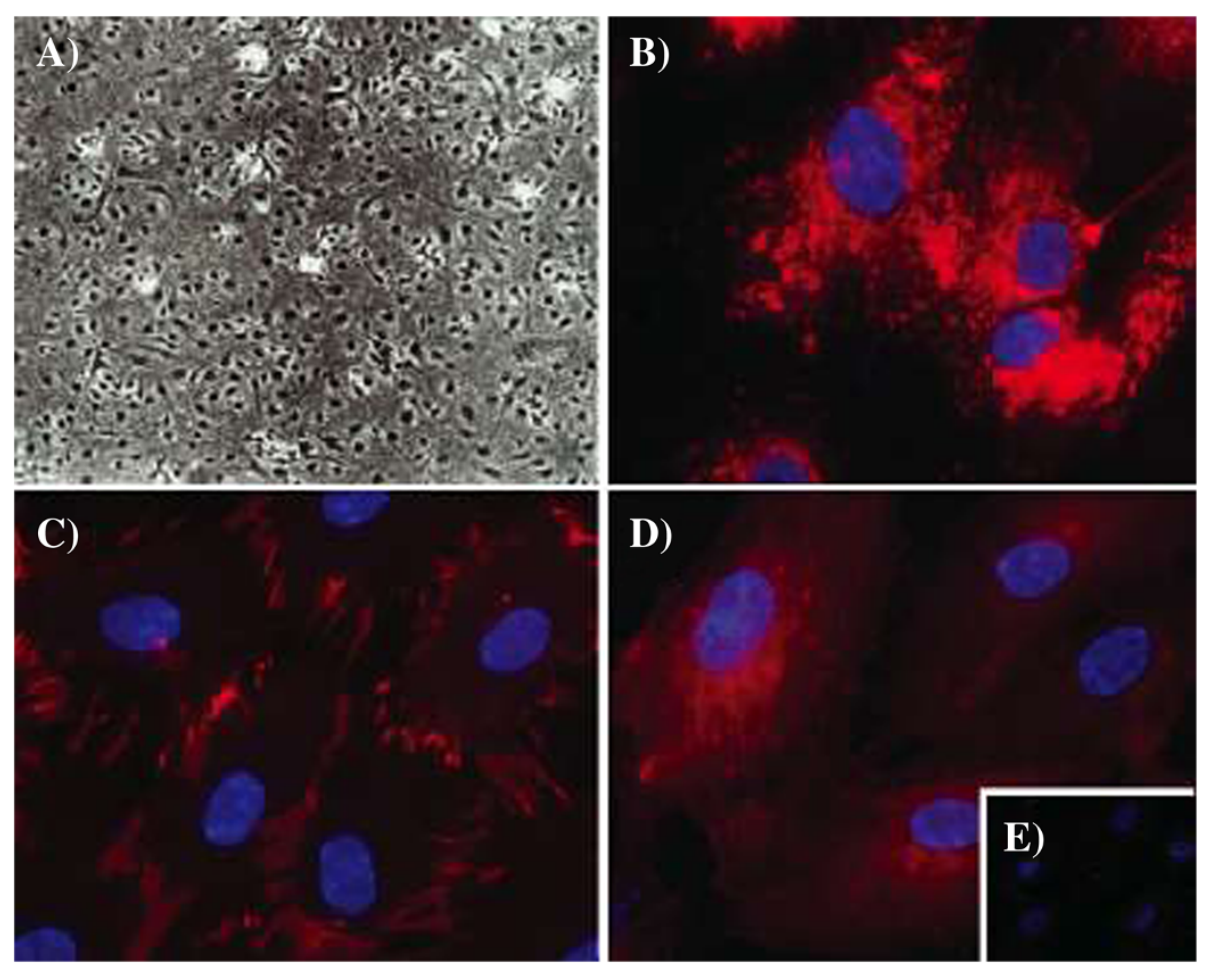

Figure 1 Characterisation of cultured human glomerular microvascular endothelial cells (HGMEC). A) Phase contrast micrograph of passage 3 purified HGMEC (magnification 200x), B and C) Immunofluorescence images of HGMEC probed for von Willebrand factor and PECAM1, respectively. D) and E) E selectin: HGMEC in panel D) were incubated for 12 hours with TNF alpha prior to fixation. No staining with $E$ selectin was observed in unstimulated cells (E). Texas red conjugated secondary antibodies were used for detection and nuclei were counter stained with Hoechst dye (blue). Original magnification in B-E was 630x.

scored below the threshold of 0.022 . Consequently, although this might be the reflection of a significant endothelial heterogeneity, only the remaining 16 endothelial cell SAGE libraries were merged to build a non-glomerular endothelial reference SAGE library for further analyses.

\section{Overlap analysis and mapping}

After verification of the endothelial origin of this library, we took advantage of the existing public data (SAGE Genie) to reduce the high number of tags to a small group of relevant and differentially expressed tags in HGMEC. The algorithm we used as the research strategy is depicted in Figure 4. First, we determined overlapping transcripts from both the HGMEC SAGE library and the ex vivo glomerular library containing 44,334 tags [17]. This showed that 823 transcripts were shared by the cultured HGMEC and the non-cultured glomeruli that contain EC. This group represented transcripts in our HGMEC SAGE library with the potential of in vivo expression. Out of these 823 transcripts (Additional file 3: Table S3) 268 were differentially overexpressed in HGMEC using Chi-square test with $\mathrm{p}<0.01$ in comparison to the non-glomerular endothelial reference SAGE library (822,008 tags) and with the restriction that the observed count in HGMEC is higher than statistically expected (see Additional file 4: Table S4 for the complete list and Table 2 for the 50 most abundant tags as well as Additional file 5: Figure S1 for expression pattern by means of a volcano plot). To test whether our statistical analysis settings were adequate we applied multiple test correction to all pvalues of the above described 823 transcripts by means of "false discovery rate (FDR)". This p-value cut-off only included tags with a false discovery rate of $<0.05$ (Additional file 4: Table S4) and was thus expected to result in less than $5 \%$ false positives. Surprisingly, this procedure led to the detection of five additional overexpressed transcripts and therefore was less stringent than our previous p-value cut-off of 0.01 with no correction (Additional file 3: Table S3, the additional five transcripts are labelled). Adding these transcripts to the set of overexpressed transcripts did not have an influence on our data or their interpretation. Nevertheless, we added the FDR corrected p-values to Table 2, Additional file 3: Table S3 and Additional file 4: Table S4. 


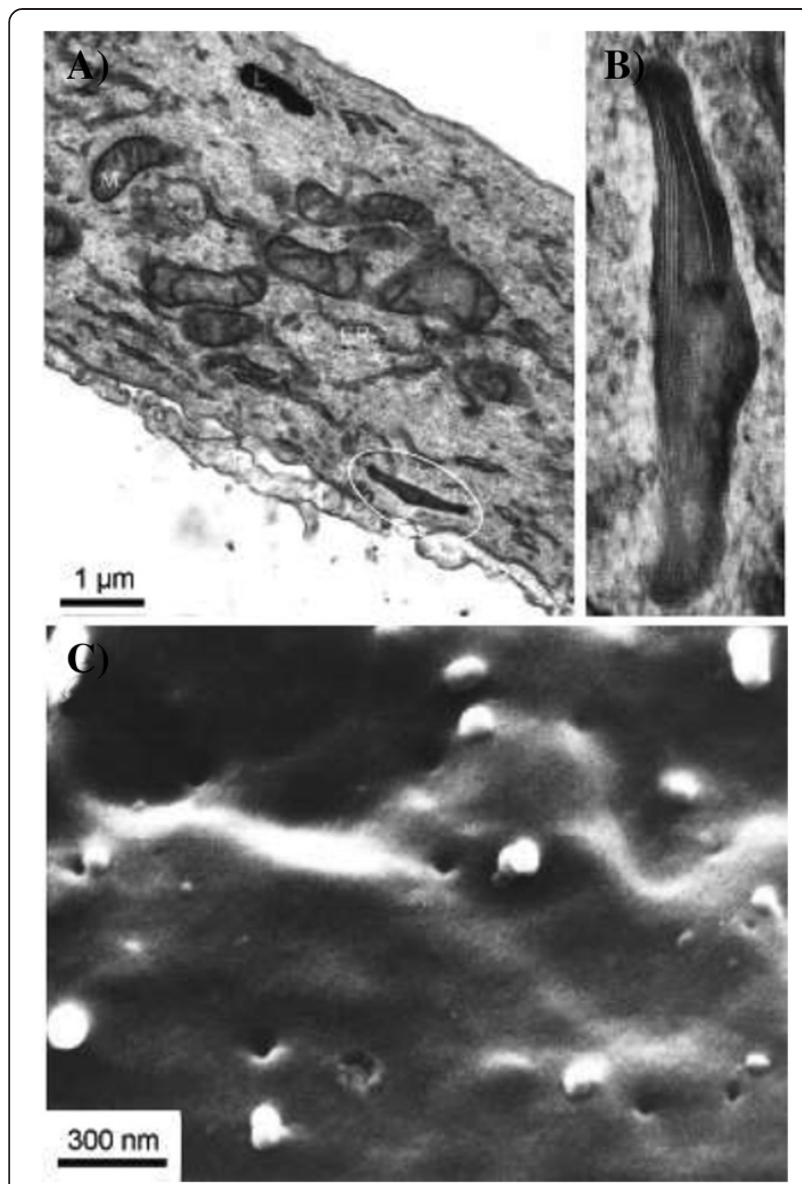

Figure 2 Electron microscopy (EM) of cultured human glomerular microvascular endothelial cells (HGMEC). A) HGMEC were cultured on nitrocellulose membranes and processed for EM. Transmission EM showing general cell structures such as lysosome (L), mitochondria (M), and endoplasmic reticulum (ER). Also the endothelial characteristic Weibel Palade bodies can be seen (circle). B) Magnification of a Weibel Palade body from panel A), showing rod shaped microtubules. C) Scanning EM of a HGMEC cell showing numerous fenestrae.

The expression of 20 randomly chosen tags from Table 2 was confirmed by quantitative RT-PCR (qRTPCR). The cytogenetic locations of the 268 transcripts are noted in Additional file 6: Figure S2. According to this analysis chromosomes 1, 6, 11, 17 and 19 are carrying $43 \%$ of these genes.

\section{Gene Ontology (GO) analysis}

We identified the GO terms present in the 268 overexpressed genes by mapping them to the GO Biological Process and determining whether they occur more often in a category than expected. We defined a category to be redundant if its child term contained the same genes. Among the 60 detected categories 12 redundant child terms were deleted. The remaining most significant categories resulted in five connected components in the Gene Ontology graph that are listed in Table 3. The known interplay between different ubiquitination processes and apoptosis in different biological systems such as TNF receptor signaling [18] is reflected in HGMEC by the overexpression of many GO terms from these biological processes. Ubiquinol to cytochrome c ("Translation and energy metabolism" cluster) and nuclear migration ("Nuclear migration" cluster) are not displayed in Table 3 despite their significant overexpression due to the small numbers of molecules in the GO-terms mitochondrial electron transport. Nonetheless, in the case of "nuclear migration" (thought to be a common process of neuroepithelia in development and enabling the migration of nucleus between apical and basal surfaces) both of the molecules in this cluster were overexpressed in HGMEC and also in the regulatory microtubule associated molecule Tpx2 [19]. This is not a high abundance molecule and yet it was clearly detected in our HGMEC SAGE library (5.8 copies/200,000). Our GO analysis demonstrates that HGMEC have high expression of ribosomal proteins (23 out of 50 most abundant tags, Table 2). Also, molecules involved in interspecies interactions and cytoskeleton organization are enriched in HGMEC. One of two other molecules of interest in the glomerular endothelium, the von Willebrand cleaving protease ADAMTS13 [GenBank: NM_139025], tag CAGGCTGAAA, was not detected in HGMEC or in any other endothelial SAGE library except in the endothelium of the normal colon (12 copies/200,000). On the other hand caveolin-1 involved in endo- and transcytosis [20] (CAV1, [GenBank: NM_001753], tag TCCTGTAAAG, has a significant expression level in HGMEC (197 copies/200,000). Interestingly, the pathway analysis in HGMEC and dermal human microvascular EC (Vascular_normal_CS_control) SAGE

Table 1 Key features of the HGMEC SAGE library

\begin{tabular}{ccccccc}
\hline Frequency & Genes & \% of genes & Tags & \% of tags & \# of reliable unique tags & \# of unique tags with no match \\
\hline $\mathbf{~} \mathbf{1 0}$ & 1,038 & 5.6 & 39,078 & 56.6 & 908 & 3 \\
$\mathbf{5 - 9}$ & 1,163 & 6.3 & 7,541 & 10.9 & 938 & 14 \\
$\mathbf{2 - 4}$ & 4,019 & 21.9 & 10,203 & 14.9 & 2,465 & 170 \\
$\mathbf{1}$ & 12,165 & 66.2 & 12,165 & 17.6 & 3,239 & 1,608 \\
Total & 18,385 & & 68,987 & & 7,550 & 1,795 \\
\hline
\end{tabular}

Distribution of tags and genes (unique tags) based on SageGenie data.

Reliable tags: All tags with a ranking according to SAGE Genie [13] greater than $80 \%$ and not from an undefined 3' end. Tags with no match: All tags with no matching tags in the SAGE Genie database. 

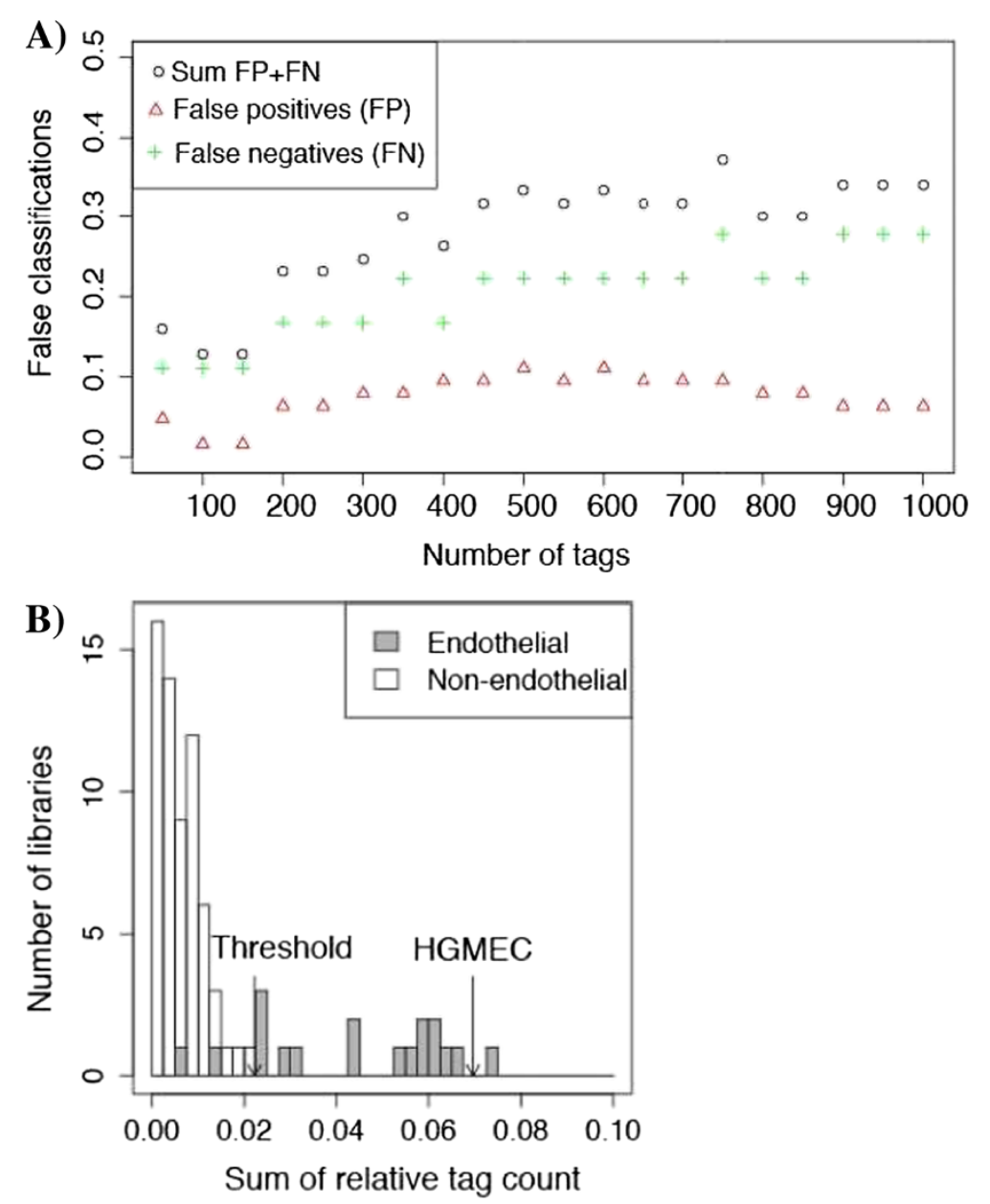

Figure 3 Classification of glomerular microvascular endothelial cell (HGMEC) library as endothelial. A) Cross-validation using 63 nonendothelial and 18 endothelial SAGE-libraries not including HGMEC SAGE library. The minimum number of false classifications (false positive: a non-endothelial library classified as endothelial and false negative: an endothelial library classified as non-endothelial) was observed for $n=100$ or 150 tags. B) Histogram showing the sum of relative expression for each of the endothelial and non-endothelial SAGE libraries as used for crossvalidation in panel A). The sum of relative tag counts of 150 tags discriminates between endothelial and non-endothelial SAGE libraries. If the sum is larger than the threshold 0.022 , the library is characterised as endothelial. This threshold is clearly exceeded by the HGMEC SAGE library (0.07).

libraries revealed novel differences regarding caveolae between these two microvascular endothelial cell types. In caveolae pathway caveolin- $1,-2$ and -3 were all present in HGMEC and absent in dermal microvascular EC. A complete list of molecules from this pathway present in HGMEC and absent in dermal microvascular EC is shown in Additional file 7: Table S5.

\section{Glomerular and non-glomerular endothelial expression of neurogranin}

To identify transcripts with the highest potential to be novel and HGMEC pre-dominant we applied the final group of transcripts of interest containing 268 tags (common to ex vivo glomeruli and differentially overexpressed in HGMEC when compared with non-glomerular endothelial cells) to a set of additional criteria: a) completely absent in all other nephron regions ex vivo [17] and b) more highly expressed than statistically expected in HGMEC. Ultimately, one transcript fulfilled all these criteria, namely NRGN. Its expression in HGMEC equalled to $192 \%$ of the statistically expected expression and it was enriched in HGMEC when compared to ex vivo glomerulus or to the fusion endothelial reference library with 52 versus 25 copies or 52 versus 21 copies per 200,000 tags, respectively. It was on position 174 when sorted from highest to the lowest expression level in the group of 268 tags (Additional file 4: Table S4). The corresponding tag for NRGN is TGACTGTGCT. Based on the SageGenie algorithm from Boon et al. [13] this tag has a high ranking of $95 \%$ and is classified as a reliable 3' end of NRGN RefSeq transcripts [NM_001126181] and [NM_006176], which strongly supported the validity of the tag. Neurogranin transcript expression in GEnC under non-permissive conditions ( 5 days at $37^{\circ} \mathrm{C}$ ) was shown by quantitative 
Initiation of the study by generation of 68,987 transcript tags from primary culture of differentiated HGMEC with fenestrations shown in scanning electron microscopy

\section{5}

CRITERION 1: find HGMEC tags potentially expressed in vivo HGMEC tags with $\geq 3$ copies compared to 444,334 transcript tags generated from ex vivo glomeruli containing endothelial cells: $\rightarrow 823$ tags of interest

CRITERION 2: find transcripts enriched in HGMEC

823 tags from the previous step compared to 822,008 tags from the nonglomerular endothelial reference SAGE library:

$\rightarrow 268$ tags of interest

\begin{tabular}{l} 
CRITERIA 3 and 4 : \\
Identify HGMEC transcripts \\
- not expressed in any other nephron segment than glomeruli \\
AND \\
- never before shown in endothelial cells \\
\hline
\end{tabular}

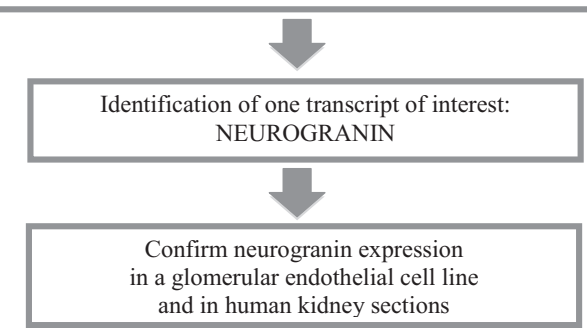

Figure 4 Short explanation of research strategy: definition of HGMEC transcriptome by generation of SAGE library and identification of HGMEC predominant transcripts based on 4 criteria. HGMEC: human glomerular microvascular endothelial cell.

RT-PCR and the 116 bp long product was cloned, sequenced and matched the NRGN RefSeq transcript [NM_001126181], 237 bp, 100\% (Figure 5). To confirm the expression of NRGN in the glomerular EC in vivo, frozen sections of human kidney were co-immunostained for NRGN (Figure 6C) and the EC marker vWF (Figure 6D). As shown in Figure 6E, both proteins show a significant co-localization confirming the transcriptional data that NRGN is expressed in the kidney's glomerular EC. No reactivity was observed with secondary antibodies alone (Figure 6A and B). The endothelial expression of NRGN is further corroborated by the in silico analysis using each of the 18 publicly available endothelial libraries considered for the reference endothelial library. We found that 14 of them expressed the NRGN tag to some extent (Table 4), with a mean number of NRGN tags per 200,000 of 27.7 (standard deviation $=20.9$ ).

Two of the four libraries which did not contain the NRGN tag, were the ones which were below the "endothelial" threshold (Figure 3B) and thus not included into the fusion endothelial reference library. The other two were "Vascular normal_CS_control" from dermal microvascular EC and "Vascular_endothelium_normal_liver_
associated_AP_NLEC1". According to these data treatment of dermal microvascular EC with vascular growth factor (VEGF) known as a differentiation factor for EC [21] led to a detectable expression of NRGN, as shown in the "Vascular normal_CS_VEGF+" library (Table 4).

\section{Discussion}

Human glomerular endothelium is composed of highly specialized cells. Their molecular features leading to the unique phenotype remain largely unknown. In this study we define the transcriptome of HGMEC using SAGE [12]. Serial analysis of gene expression gives exceptionally unbiased transcriptional data because it is based on extraction of unique sequence tags for each distinct transcript, known or unknown, differentially expressed or not, from a population of transcripts. The frequency with which a given tag is present in a SAGE library reflects the abundance of its transcript resulting in quantification of obtained data. Thus, it does not involve error prone statistics resulting from comparison to laboratory controls and thus its data are readily comparable among different laboratories. Moreover, it obtains a broader snapshot of gene expression when compared to the commercial arrays [22]. These clearly distinguish SAGE from other methods used for similar purposes. Also, in endothelial cell research SAGE has proven to be both reliable and successful [23-25]. It has to be noted that more recent and advanced high throughput sequencing methods such as deep RNA sequencing were considered for this study. This particular method displays similarities to SAGE regarding the linearity over a wide range of transcripts from low to high abundance as well as some technical advantages. It can work with significantly less starting material at a higher speed, with less work-load and cost for large sets of raw data from a single experiment to detect novel splice variants or alternative transcription sites [26,27]. Yet, SAGE was the method of choice when designing the study due to the combination of its validity and the availability of unprecedented, large, well-maintained datasets and quality-controlled databases from SAGE libraries (e.g. Cancer Genome Anatomy Project including many endothelial cell types and glomeruli).

The main challenges of transcriptional studies remain a) the sequencing errors, which was reported to account for approximately $10 \%$ of tags in SAGE [28], b) the validation of detected transcripts, c) managing the vast number of transcripts and d) not "overseeing" novel transcripts of interest which are present, but not easily "visible" in the transcript library. In this study, these issues were addressed by incorporation of advanced bioinformatics and conventional methods such as real-time PCR and immunohistochemistry. Our bioinformatics strategy allowed verification of endothelial origin of the HGMEC as well as 16 out of the 18 SAGE libraries which were publicly 
Table 2 Expression of the $\mathbf{5 0}$ most abundant from 268 tags which were common to HGMEC and ex vivo glomerular SAGE libraries and overexpressed in HGMEC in comparison to the cumulative endothelial cell library

\begin{tabular}{|c|c|c|c|c|c|c|c|}
\hline UniGene & P-value & $\begin{array}{l}\text { FDR corrected } \\
\text { p-value }\end{array}$ & Endo & HGMEC & $\begin{array}{l}\text { Expected } \\
\text { HGMEC }\end{array}$ & Description & $\begin{array}{l}\text { Confirmed } \\
\text { by RT-PCR }\end{array}$ \\
\hline hs.425125 & $0.00 \mathrm{E}+000$ & $0.00 \mathrm{E}+000$ & 145 & 551 & 88.38 & Ribosomal protein L29 (Hs00988959_gH) & + \\
\hline hs.514581 & $0.00 \mathrm{E}+000$ & $0.00 \mathrm{E}+000$ & 103 & 482 & 74.29 & Actin, gamma 1 & \\
\hline hs.586423 & $0.00 E+000$ & $0.00 E+000$ & 29 & 434 & 58.80 & $\begin{array}{l}\text { Eukaryotic translation elongation factor } 1 \text { alpha } 1 \\
(\text { Hs00265885_g1) }\end{array}$ & + \\
\hline hs.182825 & $0.00 E+000$ & $0.00 \mathrm{E}+000$ & 83 & 413 & 62.99 & Ribosomal protein L35 & \\
\hline hs.632703 & $0.00 \mathrm{E}+000$ & $0.00 \mathrm{E}+000$ & 8 & 407 & 52.70 & Ribosomal protein $L 41$ & \\
\hline hs.445351 & $0.00 \mathrm{E}+000$ & $0.00 \mathrm{E}+000$ & 33 & 394 & 54.22 & Lectin, galactoside-binding, soluble, 1 (galectin 1) & \\
\hline hs.522584 & $0.00 \mathrm{E}+000$ & $0.00 \mathrm{E}+000$ & 18 & 380 & 50.54 & Thymosin beta 4, X-linked (Hs03406519_gH) & + \\
\hline hs.374596 & $0.00 \mathrm{E}+000$ & $0.00 \mathrm{E}+000$ & 53 & 353 & 51.56 & Tumor protein, translationally-controlled 1 & \\
\hline hs.91481 & $0.00 \mathrm{E}+000$ & $0.00 \mathrm{E}+000$ & 24 & 319 & 43.56 & EGF-like-domain, multiple 7 (Hs00211952_m1) & + \\
\hline hs.523185 & $0.00 \mathrm{E}+000$ & $0.00 \mathrm{E}+000$ & 62 & 286 & 44.19 & Ribosomal protein L13a & \\
\hline hs.524910 & $0.00 \mathrm{E}+000$ & $0.00 \mathrm{E}+000$ & 32 & 252 & 36.06 & Ferritin, heavy polypeptide 1 & \\
\hline hs.546286 & $0.00 E+000$ & $0.00 E+000$ & 23 & 237 & 33.02 & Ribosomal protein S3 (Hs02385124_g1) & + \\
\hline hs.265174 & $1.96 \mathrm{E}-305$ & $1.24 \mathrm{E}-303$ & 9 & 215 & 28.45 & Ribosomal protein L32 & \\
\hline hs.494691 & $1.20 \mathrm{E}-288$ & 7.05E-287 & 199 & 355 & 70.35 & Profilin 1 (Hs00277097_m1) & + \\
\hline hs.446574 & 4.37E-285 & $2.40 \mathrm{E}-283$ & 13 & 206 & 27.81 & Thymosin beta 10 (Hs00363670_m1) & + \\
\hline hs.400295 & 4.05E-268 & $2.08 \mathrm{E}-266$ & 0 & 179 & 22.73 & Ribosomal protein $\mathrm{L} 30$ & \\
\hline hs.388664 & 8.04E-253 & $3.89 \mathrm{E}-251$ & 49 & 220 & 34.16 & Ribosomal protein L11 & \\
\hline hs.546269 & 4.36E-246 & $1.99 E-244$ & 130 & 277 & 51.68 & Ribosomal protein L10a & \\
\hline hs.433427 & $1.91 \mathrm{E}-226$ & 8.27E-225 & 45 & 198 & 30.86 & Ribosomal protein S17 & \\
\hline hs.515070 & $1.04 \mathrm{E}-224$ & 4.28E-223 & 28 & 181 & 26.54 & Eukaryotic translation elongation factor 2 & \\
\hline hs.144835 & 4.47E-213 & $1.75 \mathrm{E}-211$ & 66 & 206 & 34.54 & Eukaryotic translation elongation factor 1 gamma & \\
\hline hs.523463 & 9.00E-212 & 3.37E-210 & 50 & 192 & 30.73 & Ribosomal protein L27a (Hs00741143_s1) & + \\
\hline hs.275243 & $9.12 \mathrm{E}-204$ & $3.26 \mathrm{E}-202$ & 0 & 136 & 17.27 & S100 calcium binding protein A6 (Hs01002197_g1) & + \\
\hline hs.654404 & $1.62 \mathrm{E}-196$ & 5.56E-195 & 182 & 269 & 57.27 & Major histocompatibility complex, class I, C & \\
\hline hs.437594 & $1.55 \mathrm{E}-187$ & $5.10 \mathrm{E}-186$ & 79 & 197 & 35.05 & Ribosomal protein, large, P2 & \\
\hline hs.397609 & $1.12 \mathrm{E}-182$ & 3.55E-181 & 12 & 136 & 18.79 & Ribosomal protein S16 & \\
\hline hs.111779 & $1.18 \mathrm{E}-178$ & $3.60 \mathrm{E}-177$ & 32 & 153 & 23.49 & $\begin{array}{l}\text { Secreted protein, acidic, cysteine-rich (osteonectin) } \\
\text { (Hs00234160_m1) }\end{array}$ & + \\
\hline hs.438429 & $1.19 \mathrm{E}-170$ & 3.50E-169 & 177 & 244 & 53.46 & Ribosomal protein S19 & \\
\hline hs.605502 & 4.11E-150 & 1.17E-148 & 12 & 114 & 16.0 & $\begin{array}{l}\text { Heat shock } 70 \mathrm{kDa} \text { protein } 5 \text { (glucose-regulated protein, } \\
78 \mathrm{kDa} \text { ) (Hs00607129_gH) }\end{array}$ & + \\
\hline hs.546288 & $8.08 \mathrm{E}-149$ & $2.22 \mathrm{E}-147$ & 144 & 207 & 44.57 & Ribosomal protein $\$ 9$ & \\
\hline hs. 632717 & $1.24 \mathrm{E}-145$ & 3.29E-144 & 88 & 171 & 32.89 & $\begin{array}{l}\text { Myosin, light chain 6, alkali, smooth muscle and } \\
\text { non-muscle (Hs02597812_g1) }\end{array}$ & + \\
\hline hs.627414 & $3.86 \mathrm{E}-142$ & $9.93 \mathrm{E}-141$ & 102 & 177 & 35.43 & Ribosomal protein S18 & \\
\hline hs.381219 & 1.80E-138 & $4.49 \mathrm{E}-137$ & 10 & 104 & 14.48 & Ribosomal protein L15 & \\
\hline hs.410817 & 7.03E-122 & $1.70 \mathrm{E}-120$ & 200 & 211 & 52.19 & Ribosomal protein L13 & \\
\hline hs.511605 & $3.74 \mathrm{E}-121$ & $8.79 \mathrm{E}-120$ & 21 & 103 & 15.75 & Annexin A2 (Hs00743063_s1) & + \\
\hline hs. 17441 & $6.13 \mathrm{E}-121$ & 1.40E-119 & 28 & 109 & 17.40 & Collagen, type IV, alpha 1 (Hs00266237_m1) & + \\
\hline hs.520898 & $9.10 \mathrm{E}-117$ & $2.02 \mathrm{E}-115$ & 6 & 85 & 11.56 & Cathepsin B (Hs00947433_m1) & + \\
\hline hs.356572 & $2,11 \mathrm{E}-115$ & $2,11 \mathrm{E}-115$ & 63 & 132 & 24,76 & Ribosomal protein S3a & \\
\hline hs.170622 & $1.25 \mathrm{E}-112$ & $2.64 \mathrm{E}-111$ & 378 & 275 & 82.92 & Cofilin 1 (non-muscle) (Hs02621564_g1) & + \\
\hline
\end{tabular}


Table 2 Expression of the $\mathbf{5 0}$ most abundant from 268 tags which were common to HGMEC and ex vivo glomerular SAGE libraries and overexpressed in HGMEC in comparison to the cumulative endothelial cell library (Continued)

\begin{tabular}{|c|c|c|c|c|c|c|c|}
\hline hs.278573 & $2.63 \mathrm{E}-112$ & $5.41 \mathrm{E}-111$ & 6 & 82 & 11.17 & $\begin{array}{l}\text { CD59 molecule, complement regulatory protein } \\
\text { (Hs00174141_m1) }\end{array}$ & + \\
\hline hs.433701 & 1.37E-109 & $2.75 \mathrm{E}-108$ & 126 & 163 & 36.70 & Ribosomal protein $\mathrm{L37a}$ & \\
\hline hs.8372 & $2.40 \mathrm{E}-104$ & 4.70E-103 & 23 & 93 & 14.73 & Ubiquinol-cytochrome $\mathrm{c}$ reductase, $6.4 \mathrm{kDa}$ subunit & \\
\hline hs.527193 & 9.87E-103 & $1.89 E-101$ & 22 & 91 & 14.35 & Ribosomal protein S23 & \\
\hline hs.387208 & 8.69E-096 & 1.63E-094 & 13 & 78 & 11.56 & $\begin{array}{l}\text { Finkel-Biskis-Reilly murine sarcoma virus (FBR-MuSV) } \\
\text { ubiquitously expressed }\end{array}$ & \\
\hline hs.437191 & 1.83E-094 & 3.35E-093 & 23 & 86 & 13.84 & $\begin{array}{l}\text { Polymerase I and transcript release factor } \\
\text { (Hs00396859_m1) }\end{array}$ & + \\
\hline hs.591346 & $6.61 \mathrm{E}-094$ & 1.18E-092 & 63 & 114 & 22.48 & Connective tissue growth factor (Hs01026926_g1) & + \\
\hline hs. 644628 & 1.40E-091 & 2.45E-090 & 167 & 166 & 42.29 & Ribosomal protein $L 4$ & \\
\hline hs.77961 & 2.67E-089 & $4.58 \mathrm{E}-088$ & 44 & 98 & 18.03 & Major histocompatibility complex, class I, B & \\
\hline hs.594444 & 2.09E-088 & $3.51 \mathrm{E}-087$ & 8 & 68 & 9.65 & Lamin A/C (Hs00153462_m1) & + \\
\hline hs.446628 & $4.24 \mathrm{E}-087$ & $6.98 \mathrm{E}-086$ & 81 & 119 & 25.40 & Ribosomal protein $\mathrm{S} 4, \mathrm{X}$-linked & \\
\hline
\end{tabular}

UniGene numbers represent the UniGene groups to which the tags are assigned. P-value refers to expression comparison between HGMEC and Endo. FDR: multiple test correction using false discovery rate. Endo: Detected total copy number in the non-glomerular endothelial reference SAGE library. HGMEC: Detected copy number in HGMEC. Expected HGMEC: number of this particular tag statistically expected in HGMEC SAGE library by means of Chi-square statistics; Confirmed by RT-PCR: for these randomly chosen tags $(n=20)$ qRT-PCR was performed to confirm their expression in HGMEC. +: confirmation by qRT-PCR was successful (thus expression of all 20 transcripts confirmed by a TaqMan ${ }^{\circledR}$ Assay; each assay ID is shown in brackets).

available at the time (Table 4). The failure of two established endothelial SAGE libraries to qualify as endothelial using our methodology deserves to be mentioned. Although many possible explanations can be given for this phenomenon, we suggest that this is based on the significant differences between endothelia accounting for endothelial diversity. Nevertheless, we chose not to incorporate the transcript tags from these libraries into the non-glomerular endothelial reference library, although according to our calculations this would not change any statement or conclusion of this study. Furthermore, exclusion of singletons and comparison of HGMEC SAGE library first with ex vivo glomerular then with 16 endothelial SAGE libraries were fundamental. Only HGMECenriched tags with a significant overlap between HGMEC and ex vivo glomeruli under the simultaneous exclusion of common transcripts with non-glomerular endothelial cells were used for analyses, thus the probability of chasing tags based on sequencing errors was further minimized. Thus, expression of all the 20 randomly chosen transcripts in the resulting list of overexpressed HGMEC transcripts could be verified by qRT-PCR. Finally, robustness of our strategy was additionally validated by the demonstration of NRGN, a low-abundant molecule previously thought to be brain specific, in human glomerular endothelium in vitro and in vivo for the first time. Interestingly, although this transcript had never been known in kidney or any endothelial cell, our analysis showed that it was present in some previously generated endothelial SAGE libraries but was never recognized due to a lack of a strategy such as the one described in this study. The results from this stepwise procedure provide valuable large lists of transcripts expressed in human glomerular endothelium which have a high potential to be present in vivo and underline endothelial diversity.

Moreover, a genetic analysis of glomerular EC is especially intriguing: Not only because their uniqueness is evident in their morphology, behaviour in culture, and disease [2,29-37], but also because it is postulated that they have a distinct embryological origin and that the developing kidney generates its own endothelium [38]. Because the origin of distinct HGMEC features in vitro or in vivo is not fully understood, we defined the transcriptome of human glomerular endothelium by means of SAGE using HGMEC in culture which carried typical characteristics of differentiated glomerular endothelium including fenestrations and particularly focused on transcripts which are common to HGMEC and non-cultured ex vivo glomeruli. Only those transcripts were exposed to further analysis regarding their presence or absence in a fusion endothelial reference library. Thus, the vast numbers of transcripts were gradually reduced to manageable numbers and to relevant lists which are presented here. Next, these lists were explored in increasing depth. At first glance the remarkable abundance of ribosomal proteins in the HGMEC SAGE library was evident by the presence of 23 different ribosomal proteins among the most abundant 50 tags. We argue that this is not a mere consequence of cell culture and is a pattern found in other SAGE libraries from non-cultured cells, e.g. human monocytes (27 ribosomal proteins in the most abundant 50 transcripts) [39]. High translational activity possessed by HGMEC was reflected by the overexpression of "translation and energy metabolism" GO cluster. According to 
Table 3 Excerpt of gene ontology (GO) cluster classification

\begin{tabular}{|c|c|c|c|c|}
\hline GO ID & P-value & HGMEC count & Total count & GO Term \\
\hline \multicolumn{5}{|c|}{ Cluster 1 (Translation and energy metabolism) } \\
\hline GO:0031145 & $2.64 \mathrm{E}-004$ & 7 & 59 & $\begin{array}{l}\text { Anaphase-promoting complex-dependent proteasomal } \\
\text { ubiquitin-dependent protein catabolic process }\end{array}$ \\
\hline GO:0043161 & $2.24 \mathrm{E}-004$ & 8 & 76 & Proteasomal ubiquitin-dependent protein catabolic process \\
\hline GO:0006511 & $3.08 \mathrm{E}-003$ & 10 & 165 & Ubiquitin-dependent protein catabolic process \\
\hline GO:0044265 & 8.83E-004 & 15 & 274 & Cellular macromolecule catabolic process \\
\hline GO:0044260 & $2.60 \mathrm{E}-009$ & 81 & 2044 & Cellular macromolecule metabolic process \\
\hline GO:0043170 & $1.84 \mathrm{E}-003$ & 112 & 4217 & Macromolecule metabolic process \\
\hline GO:0006414 & 9.54E-049 & 41 & 78 & Translational elongation \\
\hline GO:0006412 & 2.67E-027 & 48 & 326 & Translation \\
\hline GO:0043284 & 3.35E-004 & 61 & 1871 & Biopolymer biosynthetic process \\
\hline GO:0009059 & $1.31 \mathrm{E}-004$ & 72 & 2251 & Macromolecule biosynthetic process \\
\hline GO:0044249 & $2.86 \mathrm{E}-004$ & 68 & 2142 & Cellular biosynthetic process \\
\hline GO:0009058 & $1.95 \mathrm{E}-003$ & 76 & 2627 & Biosynthetic process \\
\hline GO:0044237 & $5.08 \mathrm{E}-003$ & 128 & 5073 & Cellular metabolic process \\
\hline GO:0010467 & $1.39 \mathrm{E}-004$ & 74 & 2337 & Gene expression \\
\hline GO:0009987 & $2.55 \mathrm{E}-004$ & 184 & 7730 & Cellular process \\
\hline GO:0006120 & $3.76 \mathrm{E}-003$ & 4 & 30 & Mitochondrial electron transport, $\mathrm{NADH}$ to ubiquinone \\
\hline GO:0042775 & $1.27 \mathrm{E}-004$ & 6 & 37 & Organelle ATP synthesis coupled electron transport \\
\hline GO:0006119 & 1.90E-004 & 7 & 56 & Oxidative phosphorylation \\
\hline GO:0006096 & $9.71 \mathrm{E}-003$ & 4 & 39 & Glycolysis \\
\hline GO:0006091 & 5.24E-005 & 14 & 187 & Generation of precursor metabolites and energy \\
\hline \multicolumn{5}{|c|}{ Cluster 2 (Ubiquitination) } \\
\hline GO:0051437 & 4.62E-005 & 8 & 61 & $\begin{array}{l}\text { Positive regulation of ubiquitin-protein ligase activity during mitotic cell } \\
\text { cycle }\end{array}$ \\
\hline GO:0043085 & 2.93E-003 & 13 & 249 & Positive regulation of catalytic activity \\
\hline GO:0051436 & 2.37E-004 & 7 & 58 & $\begin{array}{l}\text { Negative regulation of ubiquitin-protein ligase activity during mitotic cell } \\
\text { cycle }\end{array}$ \\
\hline GO:0043086 & $8.56 \mathrm{E}-003$ & 8 & 134 & Negative regulation of catalytic activity \\
\hline \multicolumn{5}{|c|}{ Cluster 3 (Interspecies interaction) } \\
\hline GO:0044419 & $1.18 \mathrm{E}-004$ & 13 & 177 & Interspecies interaction between organisms \\
\hline GO:0051704 & $5.88 \mathrm{E}-004$ & 17 & 321 & Multi-organism process \\
\hline \multicolumn{5}{|c|}{ Cluster 4 (Apoptosis) } \\
\hline GO:0006916 & 1.15E-003 & 9 & 120 & Anti-apoptosis \\
\hline GO:0043066 & 4.15E-003 & 10 & 172 & Negative regulation of apoptosis \\
\hline GO:0051093 & $6.73 \mathrm{E}-003$ & 12 & 244 & Negative regulation of developmental process \\
\hline GO:0042981 & 4.69E-003 & 17 & 390 & Regulation of apoptosis \\
\hline GO:0006915 & $6.48 \mathrm{E}-003$ & 22 & 575 & Apoptosis \\
\hline GO:0050793 & 7.01E-003 & 22 & 579 & Regulation of developmental process \\
\hline \multicolumn{5}{|c|}{ Cluster 5 (Cytoskeleton organization) } \\
\hline GO:0030036 & $2.25 \mathrm{E}-003$ & 10 & 158 & Actin cytoskeleton organization and biogenesis \\
\hline GO:0030029 & $1.32 \mathrm{E}-003$ & 11 & 173 & Actin filament-based process \\
\hline GO:0007010 & 6.17E-003 & 16 & 368 & Cytoskeleton organization and biogenesis \\
\hline
\end{tabular}

Into this GO analysis only 268 tags were included which were expressed in ex vivo glomeruli as well predominant to HGMEC when compared to other 16 types of EC. Total count: number of molecules present in the cluster; HGMEC count: how many of the total number of molecules in a cluster are present in HGMEC; p-value: comparison between the total number of members in a cluster and the count of those which are expressed in HGMEC as a sign of enrichment. 


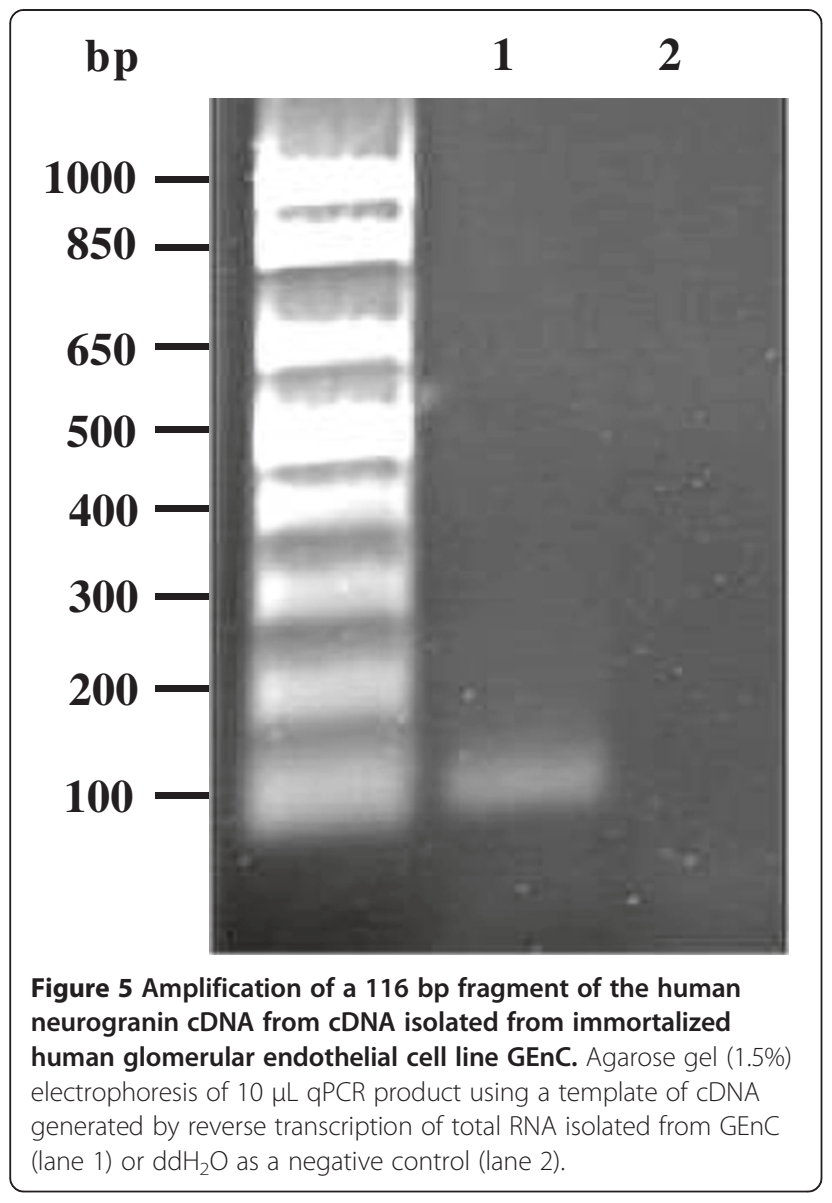

the GO analysis another cluster which was more abundant than statistically expected in HGMEC was "ubiquitination". Ubiquitination is a posttranslational modification of proteins. Monoubiquitination is involved in various processes e.g. in endocytosis or transcriptional regulation. In contrast, polyubiquitination of a protein results in recognition and degradation of this protein [40]. In this context, it is noteworthy that internalization and transport of proteins, particularly albumin, is of special interest in physiology as well as pathology of glomerular endothelium, both of which involve caveolins. A major caveolin is caveolin-1 (CAV1) which is significantly related to albumin excretion [41]. Ubiquitination seems to be responsible also for the turnover for CAV1. Hence, the presence of CAV1 in HGMEC SAGE library and enrichment of ubiquitination GO terms in addition to high concentration of ribosomal proteins substantiate the previously suggested characteristics of glomerular endothelium. Novel differences between different microvascular EC appeared by comparing caveolae pathway: in contrast to HGMEC the dermal microvascular EC (Vascular_normal_CS_control) did not express any of the caveolin 1-3 in addition to some other qualitative differences (Additional file 7: Table S5). Our results regarding the absence of ADAMTS13 in HGMEC are conflicting. The presence of this von Willebrand cleaving protease had been demonstrated in immortalized glomerular as well as in dermal microvascular EC before [42]. In most of the previously established endothelial SAGE libraries including dermal microvascular EC (Vascular_normal_CS_control and Vascular_ normal_CS_VEGF) this molecule was not detected. Neither a complete kidney (SAGE_Kidney_normal_B_1, GSM383901, data not shown) nor the liver endothelial cell SAGE library (Vascular_endothelium_normal_liver_associated_AP_NLEC1, GSM384018, Table 4) expressed any ADAMTS13 tags, although liver and kidney cells were used as positive controls in the study by Tati et al. Only the SAGE library from endothelium of normal colon expressed ADAMTS13. Probably, this is due to the low abundance of this molecule as it was demonstrated by its appearance only at high cycle numbers of RT-PCR experiments especially in human glomerular and microvascular EC [42]. It can be argued that in spite of remarkable tag numbers the sizes of the SAGE libraries were too small to detect this transcript.

Finally, when obtained transcript lists were further filtered using additional criteria (expression in HGMEC higher then statistically expected, overexpressed in HGMEC when compared to the non-glomerular endothelial reference SAGE library, never before shown in kidney or any endothelial cell type, higher expression in HGMEC than in other endothelial cell types) only one low abundance transcript, namely NRGN, stood out. It is reasonable to assume that a larger size of HGMEC SAGE library would probably lead to the detection of a higher number of NRGN tags and more transcripts fulfilling same criteria. Subsequently, we first confirmed the presence of NRGN transcript in HGMEC by sequencing and then the in vivo expression of NRGN protein in human glomerular endothelium by immunohistochemistry. Thus far, NRGN was believed to be brain specific and abundant in forebrain neurons whose interactions with calmodulin are suggested to play an important role in the regulation of synaptic responses and plasticity $[43,44]$. In brain, NRGN expression is dependent on thyroid hormones [45] and it is a direct target of thyroid hormone action [46-48]. There are numerous studies suggesting a link between thyroid and glomerular functions starting from embryogenesis [49] and involving chronic kidney disease as well as acute kidney injury [50], glomerular filtration rate [51] or resistant proteinuria [52]. Recent data in a rat model showed that proteinuria seen in hyperthyroidism is not due podocyte pathology and that hyper- as well as hypothyroidism lead to an increased capillary density when compared to control animals while hyperthyroidism resulted in an expansion of glomerular area [53]. Yet, molecules linking both organ systems have never been defined. We postulate that NRGN in glomerular endothelium represents a potential 

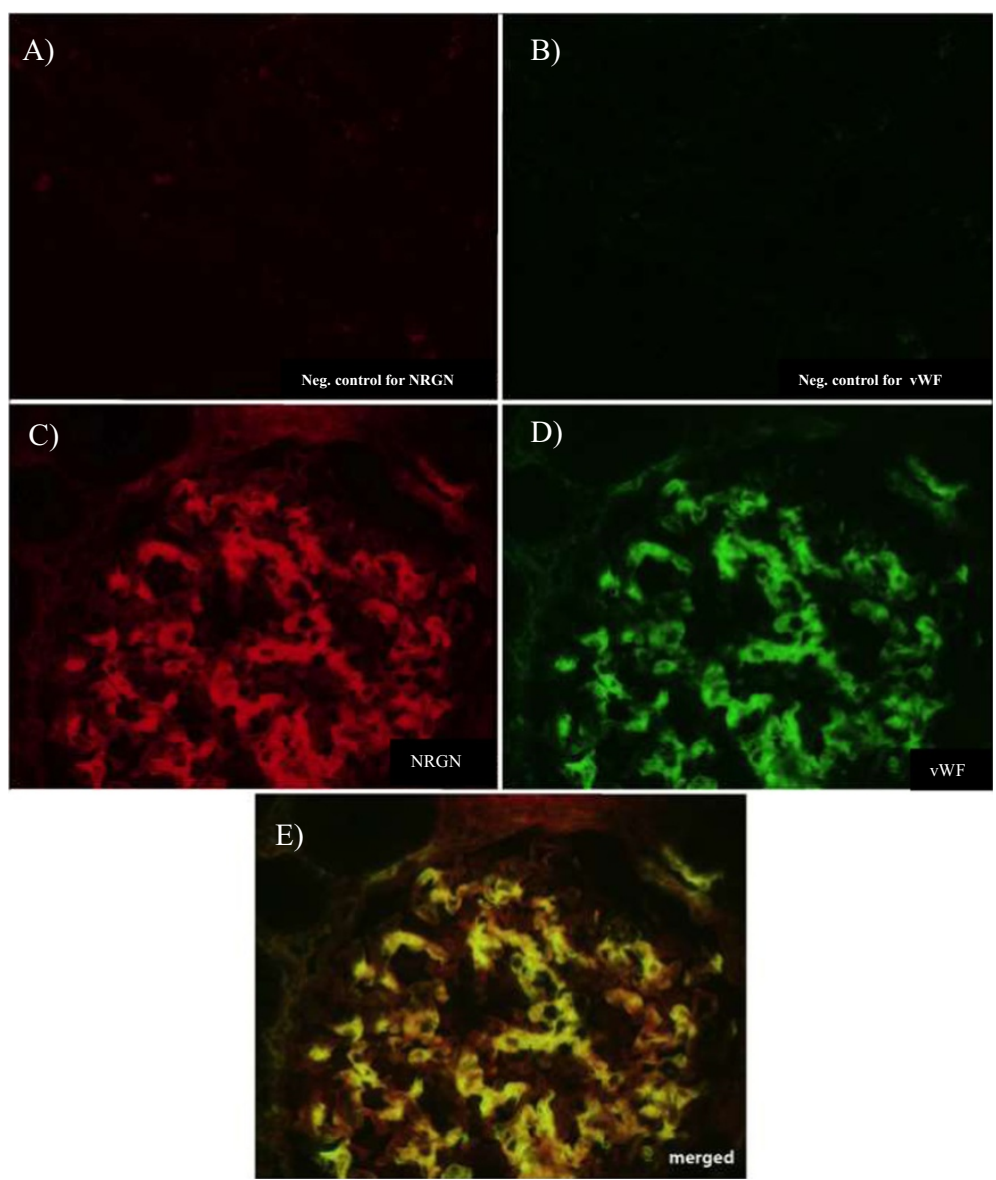

Figure 6 Immunofluorescence images of sections of human kidney showing glomerular expression of NRGN. Cryosections of human kidney were stained for neurogranin (NRGN) with anti-NRGN antibodies (C), von-Willebrand factor (VWF) with anti-vWF antibodies (D) and second antibodies alone (A and B). Signals of NRGN (red) and VWF (green) were merged in (E).

link between the kidney and the thyroid as this was described for brain and thyroid. Studies are underway to test the function of glomerular endothelial NRGN in the thyroid-kidney axis.

\section{Conclusions}

In this study we describe and analyze a HGMEC SAGE library as the first quantitative description of the human glomerular endothelial transcriptome. By using opensource SAGE data from uncultured glomeruli and from 16 other non-glomerular endothelial cell types which were merged to gain a reference endothelial library as well as by employing specific in-silico analyses an efficient research strategy was established. In this method we included an analysis to verify the declared origin of large transcript lists and strongly suggest this or similar analyses should be employed whenever using such transcript lists before including them in the studies, because $11 \%$ of the analyzed endothelial SAGE libraries failed to qualify as such. Also, integration of additional stringent filters into the bioinformatics to reduce the vast number of transcripts to manageable groups appeared to be indispensable. The described multi-step strategy which also involved GO and pathway analyses was capable of determining a list of genes potentially expressed in vivo, highlighting glomerular endothelial uniqueness as well as endothelial diversity and identifying the low abundant NRGN for the first time in glomerular endothelium and confirming its expression in vitro and in vivo. The demonstration of NRGN as a molecule potentially linking glomerulus to thyroid and the sufficiency of our transcriptomic data providing a novel insight in significant differences between the glomerular and other endothelia represent novel and exciting findings in glomerular endothelial research.

\section{Methods}

\section{Culture of primary HGMEC}

Human glomerular microvascular EC were isolated and cultured as previously described [54]. Briefly, human renal tissue was obtained, with informed consent, from macroscopically healthy pieces of nephrectomized kidneys. 
Table 4 List of all 18 non-glomerular endothelial SAGE libraries analyzed. 16 were merged to create the nonglomerular endothelial reference SAGE library

\begin{tabular}{|c|c|c|c|}
\hline SAGE library & $\begin{array}{l}\text { Number } \\
\text { of tags }\end{array}$ & $\begin{array}{l}\text { Gene expression omnibus } \\
\text { (GEO) dataset number }\end{array}$ & $\begin{array}{l}\text { Number of NRGN } \\
\text { tag per } 200,000\end{array}$ \\
\hline Vascular_endothelium_breast_carcinoma_associated_P1H12 +_AP_DCIS6 & 65223 & GSM384015 & 9 \\
\hline Vascular_endothelium_hemangioma_B_146 & 75680 & GSM384016 & 8 \\
\hline Vascular_normal_CS_control & 51562 & GSM384019 & 0 \\
\hline Vascular_normal_CS_VEGF+ & 57316 & GSM384020 & 7 \\
\hline Endothelium of normal colon & 95327 & provided by Dr. K. Kinzler & 17 \\
\hline Endothelium of colon tumor & 95543 & provided by Dr. K. Kinzler & 2 \\
\hline $\begin{array}{l}\text { Microvascular endothelial cells cultured on advanced glycatedfibronectin } \\
\text { and exposed to sustained high shear stress }\end{array}$ & 24773 & GSM45608 & 8 \\
\hline $\begin{array}{l}\text { Microvascular endothelial cells cultured on fibronectin and exposed to } \\
\text { sustained high shear stress }\end{array}$ & 30615 & GSM32266 & 19 \\
\hline $\begin{array}{l}\text { Microvascular endothelial cells cultured on fibronectin and exposed to } \\
\text { sustained low shear stress }\end{array}$ & 31141 & GSM41248 & 19 \\
\hline Vascular_endothelium_normal_liver_associated_AP_NLEC1 & 77759 & GSM384018 & 0 \\
\hline $\begin{array}{l}\text { Human Aortic Endothelial Cell Exposure to } 0 \mathrm{~h} \text { Short-Term Chronic } \\
\text { Hypoxia (Control) }\end{array}$ & 38446 & GSM62240 & 57 \\
\hline Human Aortic Endothelial Cell Exposure to 8 h Short-Term Chronic Hypoxia & 40629 & GSM62241 & 39 \\
\hline Human Aortic Endothelial Cell Exposure to 24 h Short-Term Chronic Hypoxia & 42371 & GSM62242 & 52 \\
\hline $\begin{array}{l}\text { Human Pulmonary Artery Endothelial Cell Exposure to } 0 \text { h Short-Term Chronic } \\
\text { Hypoxia (Control) }\end{array}$ & 25706 & GSM62243 & 46 \\
\hline $\begin{array}{l}\text { Human Pulmonary Artery Endothelial Cell Exposure to } 8 \mathrm{~h} \text { Short-Term } \\
\text { Chronic Hypoxia }\end{array}$ & 27666 & GSM62244 & 58 \\
\hline $\begin{array}{l}\text { Human Pulmonary Artery Endothelial Cell Exposure to } 24 \text { h Short-Term } \\
\text { Chronic Hypoxia }\end{array}$ & 42251 & GSM62245 & 47 \\
\hline Normal corneal endothelium & 9537 & GSM1652 & 0 \\
\hline Vascular_endothelium_normal breast_associated_P1H12 +_AP_1 & 34373 & GSM384017 & 0 \\
\hline
\end{tabular}

The last two libraries in italic were not included in the non-glomerular endothelial reference SAGE library based on their failure to be clearly classified of endothelial origin according to our verification analysis as explained in Methods. NRGN: neurogranin.

Written consent from patients was obtained before the surgery (Ethics Committee of the Medical University of Vienna protocol approval number EK 141/2002 047/05/ 2008 ensuring adherence to The Declaration of Helsinki). Isolated glomeruli from minced cortex were digested and plated on fibronectin coated cell culture dishes. After 7 days in cell culture medium including fetal calf serum (FCS), $50 \mu \mathrm{g} / \mathrm{mL}$ endothelial cell growth supplement, $30 \mathrm{U} / \mathrm{mL}$ heparin, $100 \mathrm{U} / \mathrm{mL}$ penicillin, $100 \mu \mathrm{g} / \mathrm{mL}$ streptomycin, and $2 \mathrm{mM}$ alanine-glutamine HGMEC constituted approx. $10 \%$ of glomerular outgrowths. HGMEC were isolated from this mixed culture using CD31 immuno-magnetic sorting as per manufacturer's instructions (Dynal, Hamburg, Germany). HGMEC were passaged 4 to 8 times.

\section{Immortalized human glomerular endothelial cell line} Conditionally immortalized GEnC line was kindly provided by Dr. Satchell and Dr. Mathieson (University of Bristol, UK) and these cells were kept as instructed [9].

\section{HGMEC characterisation}

HGMEC were seeded onto fibronectin coated glass cover slips, and cultured until near confluence prior to fixation. For immunostaining of intracellular antigens cell monolayers were permeabilised by incubation in $1 \%$ Triton-X100 for $20 \mathrm{~min}$. Non-specific binding sites were blocked by incubating $1 \mathrm{~h}$ in blocking solution (5\% (w/v) non-fat milk in phosphate-buffered saline (PBS). Primary antibody was incubated at $1 \mu \mathrm{g} / \mathrm{mL}$ for CD62P/E and CD31 and at $30 \mu \mathrm{g} / \mathrm{mL}$ for vWF for 1 hour. After probes were rinsed 3-times Texas red conjugated secondary antibody was incubated at 1:200 in antibody solution. To test the upregulation of $\mathrm{CD} 62 \mathrm{P} / \mathrm{E}$ cells were treated with human recombinant TNF alpha for 12 hours at $100 \mathrm{U} / \mathrm{mL}$.

\section{Transmission electron microscopy of HGMEC}

Human glomerular EC grown on microporous inserts were fixed with $1 \%$ glutaraldehyde, buffered with PBS, post fixed in $1 \% \mathrm{OsO}_{4}$ buffered with Na-cacodylate $(0.1 \mathrm{M})$, dehydrated in graded series of ethanol, and embedded in 
Polybed. Ultrathin sections were stained conventionally by uranyl acetate and lead citrate and were examined with a JOEL 100 C electron microscope at $100 \mathrm{KV}$.

\section{Scanning electron microscopy of HGMEC}

HGMEC were fixed with Karnowsky's fixative, post fixed in $1 \% \mathrm{OsO}_{4}$ buffered with $\mathrm{Na}$-cacodylate $(0.1 \mathrm{M})$, dehydrated in graded series of methanol, and submitted to critical point drying using $\mathrm{CO}_{2}$. Dried specimen were sputter coated with a $120 \AA$ gold palladium layer and examined with a JOEL JSM 25-S scanning electron microscope.

\section{Construction of the HGMEC SAGE library}

SAGE libraries were constructed from cultured primary HGMEC according to the short SAGE protocol [12] as described at www.sagenet.org with modifications described previously $[23,24]$.

\section{Confirmation of the endothelial origin of the HGMEC SAGE library}

To confirm the endothelial origin of HGMEC SAGE library we applied a novel classification strategy as a learning process to distinguish endothelial libraries from others. Positive examples were eighteen endothelial SAGE libraries (Table 4) not including HGMEC. Negative examples were 63 SAGE libraries from non-endothelial normal tissues obtained from SAGE Genie (Additional file 8: Table S6). Only tag counts $\geq 2$ were used and all tags which occurred in at least one of the libraries with a count $\geq 2$ were considered. These were included in a tag-wise Wilcoxon rank sum test with the null hypothesis that the median expression of each tag is equal in both classes, and the alternative hypothesis that the median expression is larger in the endothelial libraries compared to the other libraries. The strategy was to select $n$ tags highly expressed in endothelial libraries. In a subsequent step, the sum of the relative copy number of these tags was defined as an indicator for endothelial origin. The threshold was defined as the cut-off value to minimize wrong classifications based on the histogram consisting of sum of copy numbers of $n$ tags. As shown in Figure 3B the chosen threshold 0.022 resulted in only 2 wrong classifications. To determine the optimal number of tags $(n)$ to best distinguish endothelial from non-endothelial, we repeated the above described procedure using different numbers of $n$ from 50 to 1000 tags (Figure 3A). The minimum number of false classifications was observed for $\mathrm{n}=100$ or 150 (Figure 3A). We chose 150 tags as depicted in Additional file 2: Table S2 for classifying the HGMEC SAGE library. Using these tags and the threshold of 0.022 the HGMEC SAGE library was clearly classified as endothelial (Figure 3B).

\section{Construction of a non-glomerular endothelial reference SAGE library}

To obtain an endothelial reference library, sixteen endothelial SAGE libraries (Table 4) were merged to form a cumulative endothelial SAGE library as a reference library consisting of 822,008 tags.

\section{Analysis of differential expression of transcripts and tag-to-gene mapping}

First, all tags with a copy number $=1$ were eliminated from the HGMEC SAGE library. For determining the transcripts potentially present in vivo and specific for HGMEC we then combined the information present in the HGMEC SAGE library and in the ex vivo glomerular library by Chabardes-Garonne et al. [17]. We designated a transcript as being a potential HGMEC transcript if it occurred at least three times in the HGMEC SAGE library and in the ex vivo glomerular library. Each of these HGMEC transcripts was tested for overexpression compared with the cumulative non-glomerular endothelial reference SAGE library (Chi-Square-Test, $\mathrm{p}<0.01)$.

Comparisons between libraries (HGMEC, glomerular, cumulative non-glomerular endothelial reference SAGE library) were performed in a Microsoft ACCESS database. Resulting tags (common or differentially expressed among libraries) or entire tag lists from libraries were automatically identified over the web by means of "IdenTAG". IdenTAG was written in PERL specifically for this study and implemented a web-client tailored for the SAGE Genie site (http://cgap.nci.nih.gov/SAGE/AnatomicViewer) [13] of the Cancer Genome Anatomy Project at the US National Cancer Institute.

\section{Gene Ontology and pathway analysis}

For GO analysis of the overexpressed transcripts the UniGene-IDs were mapped via SAGE Genie to the corresponding Gene Symbols. Overrepresentation of genes in a GO category was determined by the Fisher test $(\mathrm{p}<$ 0.01). Subsequently, we identified the main functional categories present in these overexpressed genes by mapping them to GO Biological Process and determining whether they occur more often in a category than expected. All statistical analyses including the false discovery rate correction $(\mathrm{p}<0.05)$ and the annotation with GO Terms were performed using $\mathrm{R}$ (http://www.r-project.org) and Bioconductor (http://www.bioconductor.org). For pathway analysis the software PathwayArchitect from Stratagene (La Jolla, CA, USA) was used.

\section{Quantitative real time PCR}

An ABI Prism 7700 Sequence Detector (Applied Biosystems, California, USA) was used for mRNA quantification 
via real-time PCR. Complementary DNA from HGMEC, GEnC cultured at $37^{\circ} \mathrm{C}$ or from human brain was generated. For human NRGN (assay ID details: Hs00183469) GEnC cDNA was used. Confirmation RT-PCR reactions for the 20 randomly selected transcripts were performed using HGMEC cDNA (List of transcripts and assay ID in Table 2). Beta-actin was used as endogenous control gene (Applied Biosystems, Hs99999903_ $\mathrm{m} 1$ ). Normalization of $\mathrm{Ct}$ values of each gene ( $B$-actin and NRGN) and determination of NRGN expression in GEnC cells grown at $37^{\circ} \mathrm{C}$ was calculated according to the $2^{\Delta \Delta \mathrm{Ct}}$ method [55].

\section{Selection, cloning and sequencing of NRGN}

We searched for novel transcripts with the highest potential to be expressed in HGMEC in vivo based on 4 criteria: 1) common to ex vivo glomerulum (which consequently contains non-cultured glomerular endothelial cells) and HGMEC SAGE library; 2) complete absence in the remaining seven nephron segment SAGE libraries namely proximal convoluted tubule, proximal straight tubule, medullary thick ascending limb of Henle's loop, cortical thick ascending limb of Henle's loop, cortical collecting duct, outer medullary collecting duct and distal convoluted tubule containing approximately 350,000 tags [17]; 3) never before shown in EC, 4) enrichment of the transcript in HGMEC: observed expression higher in HGMEC when compared to the non-glomerular endothelial reference library and to the statistically expected count in HGMEC. After NRGN was recognized as the only tag fulfilling these criteria its qRTPCR product (116 bp) was purified and cloned in a pDrive cloning vector. Minipreps were prepared using the Qiaprep spin Miniprep Kit (Qiagen, Valencia, CA, USA) and vectors containing the insert were selected by EcoRI digestion and sequenced using the M13 reverse primer.

\section{Neurogranin immunofluorescence staining in human kidney sections}

For immunofluorescence, $15 \mu \mathrm{m}$ cryostat sections of human kidney tissue from the fully anonymized archive at the Department of Pathology of the Medical University of Vienna ensuring compliance to the guidelines from the Medical University of Vienna and adherence to The Declaration of Helsinki (see section "Culture of primary HGMEC" above) were fixated and blocked. They were then incubated with 1:500 rabbit anti- NRGN polyclonal or anti-vWF monoclonal antibody for 1 hour. Primary antibodies were visualized using the TSA Plus Kit (PerkinElmer, Wellesley, MA, USA) and photographed with a fluorescence microscope.

\section{Additional files} Additional file 1: Table S1. Complete HGMEC SAGE library after
exclusion of linker sequences.

Additional file 2: Table S2. List of 150 tags used for endothelial classification as described in Figure 3.

Additional file 3: Table S3. Complete list of 823 tags common to SAGE libraries from HGMEC and ex vivo glomeruli. FDR: multiple test correction by false discovery rate.

Additional file 4: Table S4. Complete list of 268 tags which are common to SAGE libraries from HGMEC and ex vivo glomeruli and overexpressed in HGMEC compared to the 16 non-glomerular endothelial cell SAGE libraries including information on cytogenetic location of each tag. FDR: multiple test correction by false discovery rate.

Additional file 5: Figure S1. Volcano plot showing p-values against log fold change for the 823 transcripts from Additional file 3: Table S3. Each red dot symbolizes one transcript which is common to HGMEC and ex vivo glomeruli and is enriched in HGMEC when compared to non-glomerular endothelial cells (268 transcripts from Additional file 4: Table S4). The plot shows a typical appearance except that because of the high $p$-values some of the sample points are accumulated on both over- (positive values on the $x$-axis) and underrepresentation (negative values on the $x$-axis) sides. Note the logarithmic scaling of the $y$-axis.

Additional file 6: Figure S2. Chromosome distribution of 268 HGMEC enriched genes as listed in Additional file 4: Table S4.

Additional file 7: Table S5. Lists of caveolae pathway molecules present in HGMEC and absent in dermal microvascular endothelial cells. Connectivity: high degree of connectivity represents proteins which are more likely to be essential for survival.

Additional file 8: Table S6. List of the 63 non-endothelial SAGE libraries which were used for the algorithm to verify the endothelial origin of a given SAGE library.

\section{Abbreviations}

Bp: Base pair; CAV1: Caveolin-1; EC: Endothelial cell; EM: Electron microscopy; GEnC: Glomerular endothelial cell; GEO: Gene expression omnibus; GO: Gene ontology; HGMEC: Human glomerular microvascular endothelial cells; NRGN: Neurogranin; PBS: Phosphate-buffered saline; PCR: Polymerase chain reaction; PECAM1: Platelet/endothelial cell adhesion molecule 1; RT-PCR: Real time polymerase chain reaction; SAGE: Serial analysis of gene expression; SEM: Scanning electron microscopy; TNF: Tumor necrosis factor; VEGF: Vascular growth factor; vWF: Von Willebrand factor.

\section{Competing interests}

The authors declare that they have no competing interests.

\section{Authors' contributions}

GS conceived the study, carried out SAGE and finalized the manuscript. WW performed RT-PCR, cloning, sequencing and drafted the manuscript. AK carried out bioinformatics and most statistical analyses. AvH participated in design and interpretation of bioinformatics data as well as in drafting the manuscript. MS wrote the script IdenTag for matching tags from SAGE libraries with public databases. WP and PJ isolated and cultured human glomerular endothelial cells and characterized them by means of immunohistochemistry as well as electron microscopy. AW had set up the initial Access database which included all SAGE libraries and in which merging of tags from different SAGE libraries was accomplished. SB carried out immunohistochemistry for von Willebrand Factor and neurogranin in human kidney sections. GSP participated in the design of the study and drafting the manuscript. All authors read and approved the final manuscript.

\section{Acknowledgements}

We gratefully acknowledge skilful technical assistance of Ms. Agnes Perschl and thank Ms. Mathilde Sengoelge and Mr. Andrew Rees for critical reading. GEnC cell line was generously provided by Dr. Simon Satchell and Dr. Peter Mathieson from the University of Bristol. This study was supported by the Austrian Science Fund (FWF) (P16129-B08) as well as the Medical Scientific Fund of the Mayor of the City of Vienna (project number 09038) granted to 
Guerkan Sengoelge. Arndt von Haeseler acknowledges financial support from the WWTF (Vienna Science Chair in Bioinformatics). Sophia Blake was funded by Long Term Fellowships from EMBO and FEBS.

\section{Author details}

'Department of Medicine III, Division of Nephrology and Dialysis, Medical University of Vienna, Waehringer Guertel 18 - 20, A-1090 Vienna, Austria. ${ }^{2}$ Center for Integrative Bioinformatics Vienna, Max F. Perutz Laboratories, Medical University of Vienna/University of Vienna, Dr. Bohr-Gasse 9, A-1030 Vienna, Austria. ${ }^{3}$ EMBL, European Bioinformatics Institute, Wellcome Trust Genome Campus, Hinxton, Cambridgeshire CB10 1SD, UK. ${ }^{4}$ Department of Physiology, Medical University of Innsbruck, Christoph-Probst-Platz 1, Innrain 52, A-6020 Innsbruck, Austria. ${ }^{5}$ Department of Haematology and Oncology, Elisabethinen Hospital, Fadingerstraße 1, A-4020 Linz, Austria. ${ }^{6}$ London Research Institute, Lincoln's Inn Fields Laboratories, Cancer Research UK, 44 Lincoln's Inn Fields, London WC2A 3LY, UK.

Received: 7 April 2014 Accepted: 15 August 2014

Published: 27 August 2014

\section{References}

1. Auerbach R, Alby L, Morrissey LW, Tu M, Joseph J: Expression of organ-specific antigens on capillary endothelial cells. Microvasc Res 1985 29:401-411

2. Craig LE, Spelman JP, Strandberg JD, Zink MC: Endothelial cells from diverse tissues exhibit differences in growth and morphology. Microvasc Res 1998, 55:65-76.

3. Stan RV, Kubitza M, Palade GE: PV-1 is a component of the fenestral and stomatal diaphragms in fenestrated endothelia. Proc Natl Acad Sci U S A 1999, 96:13203-13207.

4. Betz J, Bauwens A, Kunsmann L, Bielaszewska M, Mormann M, Humpf HU, Karch $\mathrm{H}$, Friedrich AW, Muthing J: Uncommon membrane distribution of Shiga toxin glycosphingolipid receptors in toxin-sensitive human glomerular microvascular endothelial cells. Biol Chem 2012, 393:133-147.

5. Chi JT, Chang HY, Haraldsen G, Jahnsen FL, Troyanskaya OG, Chang DS, Wang Z, Rockson SG, van de Rijn M, Botstein D, Brown PO: Endothelial cell diversity revealed by global expression profiling. Proc Natl Acad Sci U S A 2003, 100:10623-10628.

6. Jorgensen F: The Ultrastructure of the Normal Human Glomerulus Copenhagen: Munksgaard; 1966.

7. de Waard V, van den Berg BM, Veken J, Schultz-Heienbrok R, Pannekoek H, van Zonneveld AJ: Serial analysis of gene expression to assess the endothelial cell response to an atherogenic stimulus. Gene 1999, 226:1-8.

8. Amaral MM, Sacerdoti F, Jancic C, Repetto HA, Paton AW, Paton JC, Ibarra C: Action of shiga toxin type-2 and subtilase cytotoxin on human microvascular endothelial cells. PLoS One 2013, 8:e70431.

9. Satchell SC, Tasman CH, Singh A, Ni L, Geelen J, von Ruhland CJ, O'Hare MJ, Saleem MA, van den Heuvel LP, Mathieson PW: Conditionally immortalized human glomerular endothelial cells expressing fenestrations in response to VEGF. Kidney Int 2006, 69:1633-1640.

10. Satchell SC, Braet F: Glomerular Endothelial Cell Fenestrations: an Integral Component of the Glomerular Filtration Barrier. Am J Physiol Renal Physiol 2009, 296:947-956.

11. Foster RR, Armstrong L, Baker S, Wong DW, Wylie EC, Ramnath R, Jenkins R, Singh A, Steadman R, Welsh GI, Mathieson PW, Satchell SC: Glycosaminoglycan regulation by VEGFA and VEGFC of the glomerular microvascular endothelial cell glycocalyx in vitro. Am J Pathol 2013, 183:604-616.

12. Velculescu VE, Zhang L, Vogelstein B, Kinzler KW: Serial analysis of gene expression. Science 1995, 270:484-487.

13. Boon K, Osorio EC, Greenhut SF, Schaefer CF, Shoemaker J, Polyak K Morin PJ, Buetow KH, Strausberg RL, De Souza SJ, Riggins GJ: An anatomy of normal and malignant gene expression. Proc Natl Acad Sci U S A 2002, 99:11287-11292.

14. Weibel ER, Palade GE: New Cytoplasmic Components In Arterial Endothelia. J Cell Biol 1964, 23:101-112.

15. van Setten PA, van Hinsbergh W, van der Velden TJ, van de Kar NC, Vermeer M, Mahan JD, Assmann KJ, van den Heuvel LP, Monnens LA: Effects of TNF alpha on verocytotoxin cytotoxicity in purified human glomerular microvascular endothelial cells. Kidney Int 1997, 51:1245-1256.
16. Lu J, Lal A, Merriman B, Nelson S, Riggins G: A comparison of gene expression profiles produced by SAGE, long SAGE, and oligonucleotide chips. Genomics 2004, 84:631-636

17. Chabardes-Garonne D, Mejean A, Aude JC Cheval L, Di Stefano A, Gaillard MC, Imbert-Teboul M, Wittner M, Balian C, Anthouard V, Robert C, Ségurens B, Wincker P, Weissenbach J, Doucet A, Elalouf JM: A panoramic view of gene expression in the human kidney. Proc Natl Acad Sci U S A 2003 100:13710-13715.

18. Karin M, Gallagher E: TNFR signaling: ubiquitin-conjugated TRAFfic signals control stop-and-go for MAPK signaling complexes. Immunol Rev 2009 228:225-240.

19. Kosodo Y, Suetsugu T, Suda M, Mimori-Kiyosue Y, Toida K, Baba SA, Kimura A, Matsuzaki F: Regulation of interkinetic nuclear migration by cell cyclecoupled active and passive mechanisms in the developing brain. Embo $J$ 2011, 30:1690-1704.

20. Hayer A, Stoeber M, Ritz D, Engel S, Meyer HH, Helenius A: Caveolin-1 is ubiquitinated and targeted to intralumenal vesicles in endolysosomes for degradation. J Cell Biol 2010, 191:615-629.

21. Nourse MB, Halpin DE, Scatena M, Mortisen DJ, Tulloch NL, Hauch KD, Torok-Storb B, Ratner BD, Pabon L, Murry CE: VEGF induces differentiation of functional endothelium from human embryonic stem cells: implications for tissue engineering. Arterioscler Thromb Vasc Biol 2010, 30:80-89.

22. Ibrahim AF, Hedley PE, Cardle L, Kruger W, Marshall DF, Muehlbauer GJ, Waugh R: A comparative analysis of transcript abundance using SAGE and Affymetrix arrays. Funct Integr Genomics 2005, 5:163-174

23. Sengoelge $G$, Luo W, Fine D, Perschl AM, Fierlbeck W, Haririan A, Sorensson J, Rehman TU, Hauser P, Trevick JS, Kulak SC, Wegner B, Ballermann BJ: A SAGE-based comparison between glomerular and aortic endothelial cells. Am J Physiol Renal Physiol 2005, 288:F1290-F1300.

24. St Croix B, Rago C, Velculescu V, Traverso G, Romans KE, Montgomery E, Lal A, Riggins GJ, Lengauer C, Vogelstein B, Kinzler KW: Genes expressed in human tumor endothelium. Science 2000, 289:1197-1202.

25. Wang CH, Su PT, Du XY, Kuo MW, Lin CY, Yang CC, Chan HS, Chang SJ, Kuo C, Seo K, Leung LL, Chuang YJ: Thrombospondin type I domain containing 7A (THSD7A) mediates endothelial cell migration and tube formation. J Cell Physiol 2010, 222:685-694.

26. Costa V, Aprile M, Esposito R, Ciccodicola A: RNA-Seq and human complex diseases: recent accomplishments and future perspectives. Eur J Hum Genet 2013, 21:134-142.

27. Wang Z, Gerstein M, Snyder M: RNA-Seq: a revolutionary tool for transcriptomics. Nat Rev Genet 2009, 10:57-63.

28. Pleasance ED, Marra MA, Jones SJ: Assessment of SAGE in transcript identification. Genome Res 2003, 13:1203-1215.

29. Green DF, Hwang KH, Ryan US, Bourgoignie JJ: Culture of endothelial cells from baboon and human glomeruli. Kidney Int 1992, 41:1506-1516.

30. Holmen C, Elsheikh E, Christensson M, Liu J, Johansson AS, Qureshi AR, Jalkanen S, Sumitran-Holgersson S: Anti endothelial cell autoantibodies selectively activate SAPK/JNK signalling in Wegener's granulomatosis. J Am Soc Nephrol 2007, 18:2497-2508.

31. Kniesel U, Wolburg H: Tight junctions of the blood-brain barrier. Cell Mol Neurobiol 2000, 20:57-76.

32. Mitra D, Jaffe EA, Weksler B, Hajjar KA, Soderland C, Laurence J: Thrombotic thrombocytopenic purpura and sporadic hemolytic-uremic syndrome plasmas induce apoptosis in restricted lineages of human microvascular endothelial cells. Blood 1997, 89:1224-1234.

33. Nitta $K$, Uchida $K$, Yumura W, Nihei H: Characterization of the glomerular endothelial cell in culture. Nippon Jinzo Gakkai Shi 1993, 35:887-891.

34. Obrig TG, Louise CB, Lingwood CA, Boyd B, Barley-Maloney L, Daniel TO: Endothelial heterogeneity in Shiga toxin receptors and responses. $J$ Biol Chem 1993, 268:15484-15488.

35. Ott MJ, Olson JL, Ballermann B: Chronic in vitro flow promotes ultrastructural differentiation of endothelial cells. Endothelium 1995 3:21-30.

36. Roberts JM, Taylor RN, Musci TJ, Rodgers GM, Hubel CA, McLaughlin MK: Preeclampsia: an endothelial cell disorder. Am J Obstet Gynecol 1989 161:1200-1204.

37. Ryan GB: The glomerular sieve and the mechanisms of proteinuria. Aust N Z J Med 1981, 11:197-206.

38. Hyink DP, Tucker DC, St John PL, Leardkamolkarn V, Accavitti MA, Abrass CK, Abrahamson DR: Endogenous origin of glomerular endothelial and 
mesangial cells in grafts of embryonic kidneys. Am J Physiol 1996, 270:F886-F899.

39. Ishii M, Hashimoto S, Tsutsumi S, Wada Y, Matsushima K, Kodama T, Aburatani H: Direct comparison of GeneChip and SAGE on the quantitative accuracy in transcript profiling analysis. Genomics 2000, 68:136-143.

40. Hicke L: Protein regulation by monoubiquitin. Nat Rev Mol Cell Biol 2001, 2:195-201.

41. Moriyama T, Tsuruta Y, Shimizu A, Itabashi M, Takei T, Horita S, Uchida K, Nitta K: The significance of caveolae in the glomeruli in glomerular disease. J Clin Pathol 2011, 64:504-509.

42. Tati R, Kristoffersson AC, Stahl AL, Morgelin M, Motto D, Satchell S, Mathieson P, Manea-Hedstrom M, Karpman D: Phenotypic expression of ADAMTS13 in glomerular endothelial cells. PLoS One 2011, 6:e21587.

43. Huang KP, Huang FL: Calcium-sensitive translocation of Calmodulin and Neurogranin between Soma and Dendrites of Mouse Hippocampal CA1 Neurons. ACS Chem Neurosci 2011, 2:223-230.

44. Vallortigara J, Alfos S, Micheau J, Higueret P, Enderlin V: T3 administration in adult hypothyroid mice modulates expression of proteins involved in striatal synaptic plasticity and improves motor behavior. Neurobiol Dis 2008, 31:378-385.

45. Dong J, Liu W, Wang Y, Xi Q, Chen J: Hypothyroidism following developmental iodine deficiency reduces hippocampal neurogranin, CaMK II and calmodulin and elevates calcineurin in lactational rats. Int $J$ Dev Neurosci 2010, 28:589-596.

46. Iniquez MA, Rodriguez-Pena A, Ibarrola N, Aguilera M, Munoz A, Bernal J: Thyroid hormone regulation of RC3, a brain-specific gene encoding a protein kinase-C substrate. Endocrinology 1993, 133:467-473.

47. Iniguez MA, Rodriguez-Pena A, Ibarrola N, Morreale de Escobar G, Bernal J: Adult rat brain is sensitive to thyroid hormone. Regulation of RC3/ neurogranin mRNA. J Clin Invest 1992, 90:554-558.

48. Sharlin DS, Gilbert ME, Taylor MA, Ferguson DC, Zoeller RT: The nature of the compensatory response to low thyroid hormone in the developing brain. J Neuroendocrinol 2010, 22:153-165.

49. Kumar J, Gordillo R, Kaskel FJ, Druschel CM, Woroniecki RP: Increased prevalence of renal and urinary tract anomalies in children with congenital hypothyroidism. J Pediatr 2009, 154:263-266.

50. Iglesias P, Diez JJ: Thyroid dysfunction and kidney disease. Eur J Endocrinol 2009, 160:503-515.

51. Suher $M, \operatorname{Koc} E$, Ata $N$, Ensari C: Relation of thyroid disfunction, thyroid autoantibodies, and renal function. Ren Fail 2005, 27:739-742.

52. Rodriguez-Gomez I, Sainz J, Wangensteen R, Moreno JM, Duarte J, Osuna A, Vargas F: Increased pressor sensitivity to chronic nitric oxide deficiency in hyperthyroid rats. Hypertension 2003, 42:220-225.

53. Rodriguez-Gomez I, Banegas I, Wangensteen R, Quesada A, Jimenez R, Gomez-Morales M, O'Valle F, Duarte J, Vargas F: Influence of thyroid state on cardiac and renal capillary density and glomerular morphology in rats. J Endocrinol 2013, 216:43-51.

54. Aydin S, Signorelli S, Lechleitner T, Joannidis M, Pleban C, Perco P, Pfaller W, Jennings $P$ : Influence of microvascular endothelial cells on transcriptional regulation of proximal tubular epithelial cells. Am J Physiol Cell Physiol 2008, 294:C543-C554.

55. Livak KJ, Schmittgen TD: Analysis of relative gene expression data using real-time quantitative PCR and the 2(-Delta Delta $C(T)$ ) Method. Methods 2001, 25:402-408.

doi:10.1186/1471-2164-15-725

Cite this article as: Sengoelge et al:: A SAGE based approach to human glomerular endothelium: defining the transcriptome, finding a novel molecule and highlighting endothelial diversity. BMC Genomics 2014 15:725.

\section{Submit your next manuscript to BioMed Central and take full advantage of:}

- Convenient online submission

- Thorough peer review

- No space constraints or color figure charges

- Immediate publication on acceptance

- Inclusion in PubMed, CAS, Scopus and Google Scholar

- Research which is freely available for redistribution

Submit your manuscript at www.biomedcentral.com/submit
C Biomed Central 